\title{
Aspects of the Pathogenesis and Management of Inflammatory Bowel Diseases
}

\author{
Andrew S. Day (1)
}

check for updates

Citation: Day, A.S. Aspects of the Pathogenesis and Management of Inflammatory Bowel Diseases.

Gastrointest. Disord. 2021, 3, 96-99. https://doi.org/10.3390/

gidisord 3030010

Received: 24 July 2021

Accepted: 26 July 2021

Published: 28 July 2021

Publisher's Note: MDPI stays neutral with regard to jurisdictional claims in published maps and institutional affiliations.

Copyright: (C) 2021 by the author. Licensee MDPI, Basel, Switzerland. This article is an open access article distributed under the terms and conditions of the Creative Commons Attribution (CC BY) license (https:// creativecommons.org/licenses/by/ $4.0 /)$.
Department of Paediatrics, University of Otago Christchurch, Christchurch 8011, New Zealand; andrew.day@otago.ac.nz

\section{Background}

Over the last two decades, inflammatory bowel disease (IBD) has been diagnosed more often in many countries around the world, including in parts of the world where IBD was previously uncommon [1]. IBD, characterised as chronic gut inflammation with a relapsing/remitting clinical pattern, can be classified into one of two main types: Crohn's disease (CD) or ulcerative colitis (UC) [2]. A further subtype is IBD Unclassified (IBDU).

The most accepted hypothesis for the development of IBD is that microbiological and environmental factors trigger immune responses in a host with an underlying genetic risk to prompt inflammatory changes in the gut [2,3]. Although various interventions can and are used to manage IBD, none of these therapies are curative. Consequently, an individual diagnosed with $\mathrm{CD}$ or UC has a life-long disease that may result in the interruption of growth and nutrition, may affect life choices or employment, and have adverse psychological effects.

The current Special Issue includes manuscripts that focus on specific elements of the pathogenesis of IBD, some considerations of the components of IBD management, and aspects of the impact of the disease from the perspective of the patient.

\section{Pathogenesis of IBD}

The intestinal epithelium is a key component of the barrier between the luminal contents and the body [4]. Disruption of one or more components of the intestinal barrier can contribute to the development of various diseases including IBD. Key aspects of intestinal barrier function include gut motility (thereby avoiding stasis), the inner and outer mucous layers, epithelial tight junctions, and specialised epithelial cell functions (such as Paneth cells producing defensins, innate defence proteins). Maintaining homeostasis while responding appropriately to any insult is a key function of the gut mucosa.

Ranjan [5] and Li [6] reviewed specific aspects of cellular stress consequent to perturbations in mucosal homeostasis as key aspects in the pathophysiology of IBD with a particular focus on the unfolded protein response (UPR) and endoplasmic reticulum (ER) stress. Li [6] discusses the roles of macrophages and mesenchymal cells in the UPR and highlights recent data regarding the regulation and maintenance of this key response. To complement this work, Ranjan [5] provides a comprehensive review of the relevance of the UPR and mitochondrial contributions to oxidative stress while highlighting the key signalling pathways involved.

Both these reviews also highlight how advances in the understanding of these pathways open the possibility of focused therapeutic interventions. Ranjan [5] discusses several current and prospective agents that modify aspects of the complex network involved in ER stress and UPR. For example, glutamine has been shown to alleviate ER stress in an animal model [7]. Li [6] also raises a number of gaps in our understanding, posing these as key components of future studies focused upon these mechanisms that again may unlock therapeutic options. 
The presence of multi-nucleated giant cells (granuloma) in the intestinal mucosa is a key feature of CD but not of UC [2]. Studies have shown that granuloma may be present in up to two thirds of individuals with CD. Appleton and colleagues [8] described the features of 94 children diagnosed with CD. The disease features and outcomes of the subgroup who were noted to have granulomata present were contrasted with those without granuloma. The presence of one or more granuloma was associated with greater adverse impacts on nutrition, disease location, and a more severe disease course. While this was a relatively small group of children with $C D$, it does emphasize the potential relevance of the finding of granulomata on disease course and outcomes.

\section{Management of IBD}

Following diagnosis, the management of CD and UC relies upon initial interventions that reduce inflammation (induce remission) and further therapies that help to maintain remission [2]. Management requires the introduction of therapeutic targets or objectives and relies upon the ongoing monitoring of the disease status. Furthermore, the ongoing management of IBD requires assessment and monitoring of many other aspects beyond therapeutic interventions including nutrition, growth, psychological well-being, educational or employment attainments, and social interactions.

A number of the drugs used for IBD are immunosuppressives and can result in an increased risk of various infections. In this context, protecting individuals with IBD from these adverse outcomes is important. Casella et al. [9] review the role of vaccinations in individuals with IBD, especially in the context of immunosuppression. They provide an overview of the relevance of documenting the vaccination status and highlighting vaccination while also clarifying the risks of vaccination.

While there are various therapies available for the management of IBD, none are curative. Miki and colleagues [10] describe the development and assessment of a pegylated form of adrenomedullin in an animal model of colitis. Preliminary data has demonstrated that adrenomedullin has anti-inflammatory effects but these are limited by its short halflife. Pegylated adrenomedullin, administered intermittently via subcutaneous injection, reduced but did not prevent the inflammatory changes in this murine model of colitis. This preliminary pre-clinical data suggests a potential role in the management of IBD.

Although many of the interventions to induce or maintain remission involve drugs, dietary interventions are increasingly being considered. In particular, exclusive enteral nutrition (EEN), involving a period of a completely liquid formula and exclusion of normal table foods, is recommended internationally as the primary therapy to induce remission in children [11] and is also used commonly in adults in some locations [12]. Solomon et al. [13] reviewed aspects of dietary therapies in IBD, highlighting several of the options available in addition to EEN. They also discuss some patient perspectives of these interventions.

\section{Patient Perspectives of Inflammatory Bowel Disease}

While rates of IBD have increased in many countries, even within countries with high rates and quality healthcare systems, inequities of care remain. These include issues such as "post-code" access to therapies and variable access to resources (e.g., psychology support). Farrukh and Mayberry [14] reported data on variable rates of hospitalisation and biologic therapy access in some minority populations in parts of England. This manuscript highlighted variations in care in individuals of Afro-Caribbean and Eastern European background. While the impact of these variations in care upon patient outcomes was not considered, these data are clearly concerning.

Following diagnosis, IBD is an incurable and life-long disease. In many cases, this can adversely impact quality of life (QOL) especially if the disease is not well controlled. Thi Thanh Tran et al. [15] explored aspects of QOL in 300 Japanese patients with IBD. Japan amended their medical support scheme in 2015 to ensure that individuals with a mild disease that were ineligible for additional financial support for their disease management received care. This current work aimed to assess if this policy adversely impacted the 
QOL of patients with mild disease. The authors concluded that there was no relationship between the eligibility status of the respondents and their QOL [15].

Learning about their disease is a key event following an individual's diagnosis of IBD. Various tools have been developed and validated as ways to define and assess diseasespecific knowledge. Appleton and Day [16] cross-sectionally evaluated the knowledge of 66 patients with IBD and 153 of their parents utilising the well-validated IBD-Knowledge Inventory Device (IBD-KID). As expected, parents had greater knowledge scores than their children. Gaps in knowledge were identified in both groups: these included longterm outcomes of IBD and aspects of treatments. This study did not evaluate changes in knowledge over time or the impact of educational interventions in this group. The IBD-KID tool may enable the identification of gaps, permitting focused education.

The acquisition of disease-specific knowledge is just one part of a patient's management of their disease. Knowledge can be encapsulated in addition to adherence, selfregulation, and communication as self-management skills. Vernon-Roberts et al. [17] reviewed various devices and approaches related to the assessment and monitoring of self-management. As the authors highlight, this is especially relevant for the adolescent moving from a paediatric care system (in which the patient, parent, and health care provider work together) to an adult care system (which is more focused on the patient and their health-care provider). Self-management skills, however, have a broader relevance for all patients navigating their IBD journey.

In conclusion, this Special Issue covers a range of topics relevant to the pathogenesis and management of IBD. Further studies also illustrate the importance of patient aspects regarding the management of this incurable chronic condition. Maintaining a holistic approach is crucial for optimising the outcomes of patients with IBD.

Conflicts of Interest: The author declares no conflict of interest.

\section{References}

1. Ng, S.C.; Shi, H.Y.; Hamidi, N.; Underwood, F.E.; Tang, W.; Benchimol, E.I.; Panaccione, R.; Ghosh, S.; Wu, J.C.Y.; Chan, F.K.L.; et al. Worldwide incidence and prevalence of inflammatory bowel disease in the 21st century: A systematic review of population-based studies. Lancet 2017, 390, 2769-2778. [CrossRef]

2. Day, A.S.; Lemberg, D.A. Identification and diagnosis of Crohn disease and ulcerative colitis in children. J. Paediatr. Child Health 2020, 56, 1731-1734. [CrossRef] [PubMed]

3. Goethel, A.; Croitoru, K.; Philpott, D.J. The interplay between microbes and the immune response in inflammatory bowel disease. J. Physiol. 2018, 596, 3869-3882. [CrossRef] [PubMed]

4. Puértolas-Balint, F.; Schroeder, B.O. Does an Apple a Day Also Keep the Microbes Away? The Interplay Between Diet, Microbiota, and Host Defense Peptides at the Intestinal Mucosal Barrier. Front. Immunol. 2020, 11, 1164. [CrossRef] [PubMed]

5. Ranjan, K. Intestinal Immune Homeostasis and Inflammatory Bowel Disease: A Perspective on Intracellular Response Mechanisms. Gastrointest. Disord. 2020, 2, 246-266. [CrossRef]

6. Li, C. Unfolded Protein Response and Crohn's Diseases: A Molecular Mechanism of Wound Healing in the Gut. Gastrointest. Disord. 2021, 3, 31-43. [CrossRef]

7. Crespo, I.; San-Miguel, B.; Prause, C.; Marroni, N.; Cuevas, M.J.; González-Gallego, J.; Tuñón, M.J. Glutamine Treatment Attenuates Endoplasmic Reticulum Stress and Apoptosis in TNBS-Induced Colitis. PLoS ONE 2012, 7, e50407. [CrossRef] [PubMed]

8. Appleton, L.; Watt, E.; Jagger, F.; Hansen, R.; Gearry, R.B.; Day, A.S. Associations between the Presence of Granulomata and Disease Phenotype and Outcomes in Children Diagnosed with Crohn's Disease. Gastrointest. Disord. 2020, 2, 17. [CrossRef]

9. Van Rheenen, P.F.; Aloi, M.; Assa, A.; Bronsky, J.; Escher, J.C.; Fagerberg, U.L.; Gasparetto, M.; Gerasimidis, K.; Griffiths, A.; Henderson, P.; et al. The Medical Management of Paediatric Crohn's Disease: An ECCO-ESPGHAN Guideline Update. J. Crohn's Coliti 2021, 15, 171-194. [CrossRef] [PubMed]

10. Wall, C. Use of exclusive enteral nutrition in adults with Crohn's disease: A review. World J. Gastroenterol. 2013, 19, 7652-7660. [CrossRef] [PubMed]

11. Solomon, S.; Park, E.; Picoraro, J.A. Making Decisions about Dietary Therapy in Inflammatory Bowel Disease. Gastrointest. Disord. 2020, 2, 32. [CrossRef]

12. Casella, G.; Ingravalle, F.; Ingravalle, A.; Monti, C.; Bonetti, F.; De Salvatore, F.; Villanacci, V.; Limonta, A. Vaccination in Inflammatory Bowel Disease: Utility and Future Perspective. Gastrointest. Disord. 2020, 2, 19. [CrossRef]

13. Miki, G.; Kuroishi, N.; Tokashiki, M.; Nagata, S.; Tamura, M.; Yoshiya, T.; Yoshizawa-Kumagaye, K.; Ashizuka, S.; Kato, J.; Yamasaki, M.; et al. $20 \mathrm{kDa}$ PEGylated Adrenomedullin as a New Therapeutic Candidate for Inflammatory Bowel Disease. Gastrointest. Disord. 2020, 2, 33. [CrossRef] 
14. Farrukh, A.; Mayberry, J. Apparent Disparities in Hospital Admission and Biologic Use in the Management of Inflammatory Bowel Disease between 2014-2018 in Some Black and Ethnic Minority (BEM) Populations in England. Gastrointest. Disord. 2020, 2, 15. [CrossRef]

15. Tran, H.T.T.; Saito, S.; Noto, S.; Suzuki, K. Quality of Life and Eligibility for Specific Financial Assistance for Medical Expenses: A Cross-Sectional Web-Based Survey among Patients with Inflammatory Bowel Disease in Japan. Gastrointest. Disord. 2020, 2, 12. [CrossRef]

16. Appleton, L.; Day, A.S. Disease-Related Knowledge in New Zealand Children with Inflammatory Bowel Disease (IBD) and Their Parents. Gastrointest. Disord. 2021, 3, 2. [CrossRef]

17. Vernon-Roberts, A.; Gearry, R.; Day, A. Overview of Self-Management Skills and Associated Assessment Tools for Children with Inflammatory Bowel Disease. Gastrointest. Disord. 2021, 3, 7. [CrossRef] 